\title{
400 bài báo khả nghi và câu chuyện "công xưởng làm giả nghiên cứu"
}

\author{
Lương Anh Phương \& Hồ Mạnh Toàn
}

AISDL

Hà Nội, ngày 6 tháng 3 năm 2020

SSHPA EASE Vietnam SciComm (06-03-2020; https://sc.sshpa.com/post/5634) - Dưới áp lực của các quy định về công bố khoa học, nhiều nhà nghiên cứu đã tìm đến các "lối tắt". Mới đây, nhà vi sinh và chuyên gia về đạo đức học thuật Elisabeth Bik và các cộng sự sử dụng bút danh Smut Clyde, Morty và Tiger BB8, và một số nhà điều tra khác như Jennifer A. Byrne (University of Sydney, Úc), Jana Christopher (Heidelberg University Biochemistry Center, Đức), đã lên tiếng về vấn nạn "công xưởng làm giả nghiên cứu", cũng như đưa tin ít nhất 400 bài báo khoa học có thể đang sử dụng hình ảnh chỉnh sửa. Rất nhiều các bài báo này được đăng trên các tạp chí của các nhà xuất bản lớn như Wiley, Elsevier, hay Taylor \& Francis. Đồng thời, dường như chúng đều được sản xuất từ cùng một khuôn.

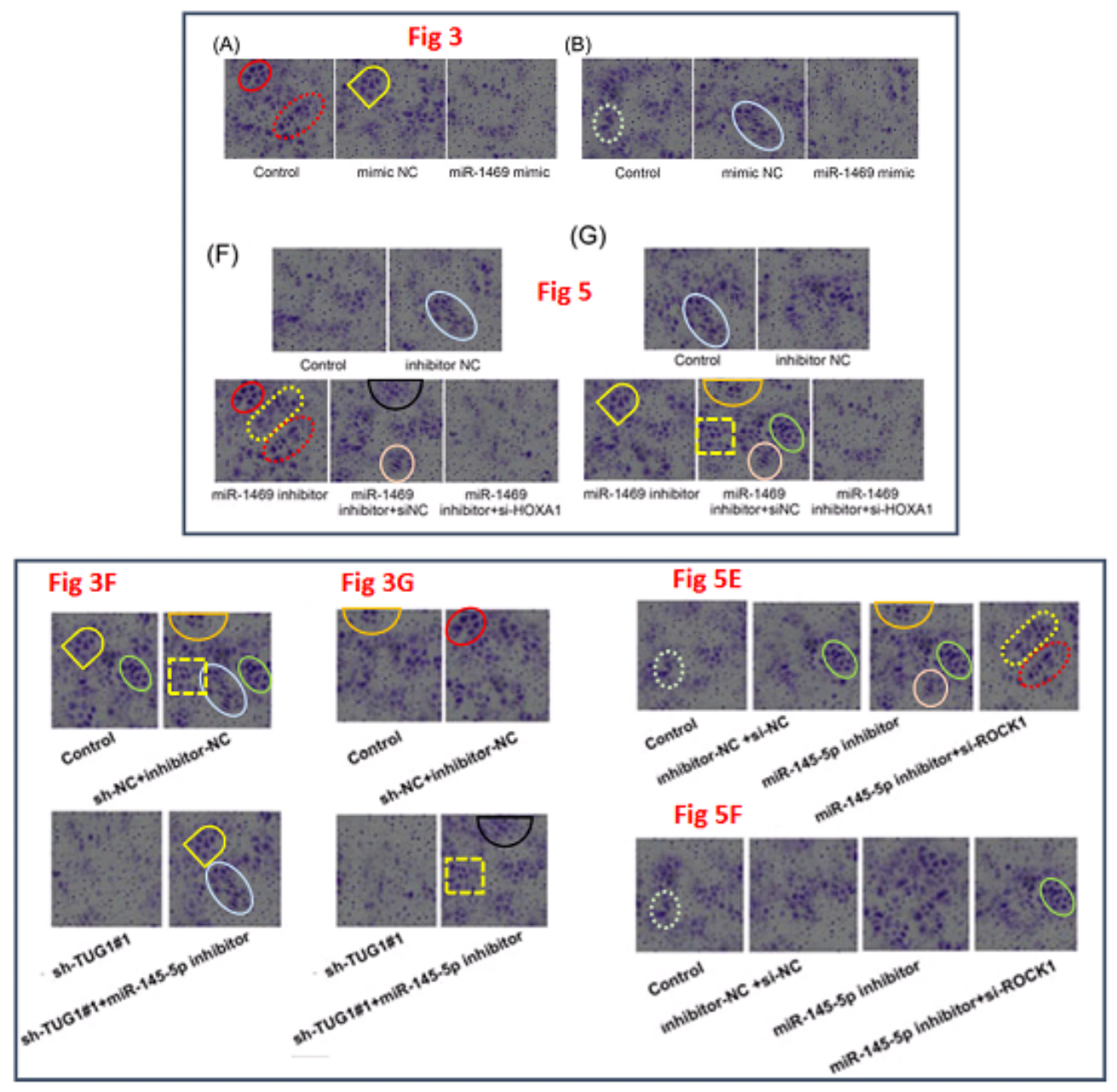


Từ năm 2018, hai tác giả Jennifer A. Byrne, Jana Christopher đã có các bài viết cảnh báo về hiện tượng "công xưởng làm già nghiên cứu" trên FEBS Letters. Đến ngày 21-02-2020, vụ việc 400 bài báo có vấn đề, bao gồm cả các bài báo mà Byrne và Christopher đã cảnh báo, được Elisabeth Bik và các cộng sự đăng tải trên blog cá nhân của Bik. Vụ việc sau đó đã được các tạp chí, trang truyền thông khoa học lớn đưa tin như Science, For Better Science, hay Retraction Watch.

Nhóm điều tra đã phát hiện ra hàng loạt bài báo khoa học sử dụng các hình ảnh western blotvốn được dùng trong sinh học phân tử để làm rõ hình ảnh của proteins-có phông nền rất giống nhau và các dải hình gọn gàng một cách bất thường. Bên cạnh đó, các chi tiết khác như phong cách hình bảng, hay cấu trúc tên bài có sự tương đồng xuyên suất giữa hơn 100 bài nghiên cứu cũng làm các nhà điều tra nghi ngờ.

Elisabeth Bik và các cộng sự cũng cho biết thêm rất nhiều các bài báo đáng nghi này có các tác giả tới từ các bệnh viện hay các trường y tại Trung Quốc. Số lượng lớn các bài báo này cũng thường viết về chủ đề y học cổ truyền Trung Quốc trong việc điều trị ung thư và các bệnh ác tính khác, vốn là một đề tài đang được Trung Quốc đầu tư nghiên cứu.

Chia sẻ trên For Better Science, Smut Clyde cho biết các "công xưởng làm giả nghiên cứu" ra đời một phần nhằm phục vụ nhu cầu công bố quốc tế của các bác sĩ lâm sàng tại Trung Quốc. Dù phần lớn thời gian đã dành trong phòng phẫu thuật hay chữa trị bệnh nhân, các bác sĩ lâm sàng tại Trung Quốc lại phải đối mặt với yêu cầu bài vở rất cao, vì số lượng bài công bố quốc tế đang là một trong các thước đo quan trọng cho việc thăng chức.

Vì vậy, cũng dễ hiểu khi các 'công xưởng' mọc lên với đầy đủ "dịch vụ", bao gồm: bài viết hoàn chỉnh bằng Tiếng Anh, dữ liệu làm giả bằng phần mềm Photoshop, đăng bài hay thậm chí trả lời phản biện hộ. Bên cạnh kiểm tra các dâuu vết từ hình ảnh, dữ liêu trong bài báo, nhóm điều tra còn phát hiện ra các tác giả từ Trung Quốc sử dụng Google Mail để gửi bài và nhận phản biện (dù các dịch vụ Mail của Google đã bị chặn bởi Trung Quốc từ năm 2014). Ngoài ra, còn xuất hiện tình trạng một tác giả có đến 2, 3 tài khoản ORCID. 


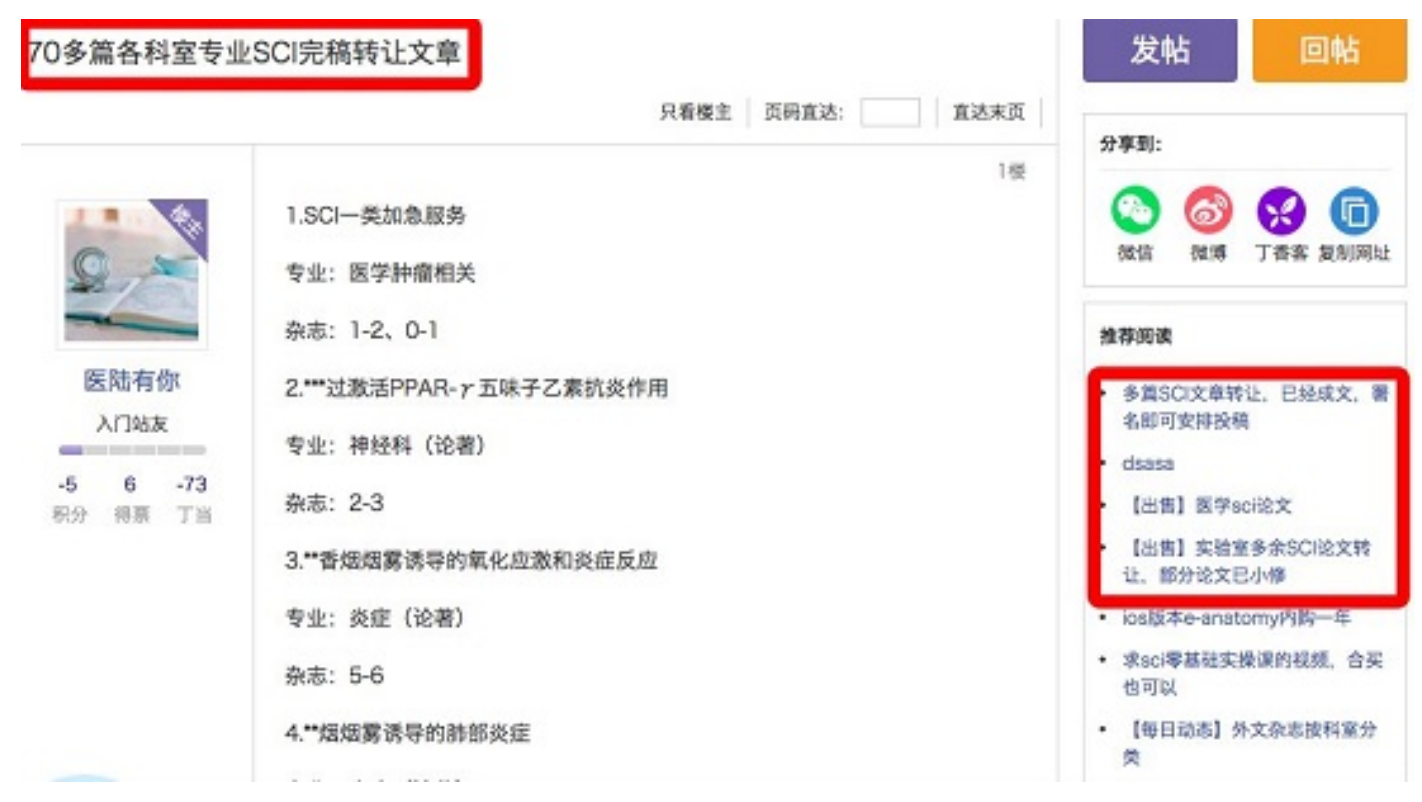

Một trang web bán bài công khai:

Ô đỏ ở trên cùng: hơn 70 bản thảo y khoa còn tồn kho.

Ô đỏ ở dưới, điểm 1: còn rất nhiều bản thảo SCI. Đã viết đầy đủ. Chúng tôi sẽ nộp với tên bạn.

Điểm 4: Lab chúng tôi còn rât nhiều bản thảo SCI. Một số đã được binh duyệt và đang sửa. (Nguồn: For Better Science)

Chỉ với 4 người, nhóm điều giả của Elisabeth Bik và các cộng sự đã có thể tìm ra hơn 400 bài báo với nhiều điểm nghi vấn. Rõ ràng, số lượng các nghiên cứu thực tế có thể còn nhiều hơn. Hiện tại, chia sẻ với Science, đội ngũ biên tập của các tạp chí đã đăng các bài báo đáng nghi ngờ đều đang liên lạc với các tác giả, và phối hợp cùng với nhà xuất bản đề điều tra kĩ vụ việc. Chắc chắn, số lượng bài bị rút sẽ rất cao.

Theo tác giả Elisabeth Bik, kiểm tra hình ảnh và dữ liệu cần trở thành một phần thiết yếu của quá trình bình duyệt và biên tập tiền xuất bản. Đồng thời, các nhà xuất bản cũng cân có sự đầu tư tốt hơn để đảm bảo quá trình bình duyệt bản thảo, tránh chỉ dựa vào các tay bút bình duyệt, vốn không được trả lương và không được đào tạo, cũng như các đội kiểm tra tình nguyện sau xuất bản để phát hiện sai phạm.

\section{*Tài liệu tham khảo:}

Schneider, L. (2020). The full-service paper mill and its Chinese customers. For Better Science. URL: https://forbetterscience.com/2020/01/24/the-full-service-paper-mill-and-itschinese-customers/

Bik, E. (2020). The Tadpole Paper Mill. Scientific Integrity Digest. URL: https://scienceintegritydigest.com/2020/02/21/the-tadpole-paper-mill/ 
Byrne, J. A., \& Christopher, J. (2020). Digital magic, or the dark arts of the 21 st century-how can journals and peer reviewers detect manuscripts and publications from paper mills?. FEBS Letters, 594(4), 583-589, DOI: 10.1002/1873-3468.13747

Chawla, D. S. (2020). A single 'paper mill' appears to have churned out 400 papers, sleuths find. Science, doi:10.1126/science.abb4930.

Vuong, Q. H. (2020). Retractions: the good, the bad, and the ugly. LSE Impact of Social Sciences (Feb 20). URL:

https://blogs.Ise.ac.uk/impactofsocialsciences/2020/02/20/retractions-the-good-the-badand-the-ugly-what-researchers-stand-to-gain-from-taking-more-care-to-understanderrors-in-the-scientific-record/ 